\title{
The Effect of Sampling Inlet Direction and Distance on Particle Source Measurements for Dispersion Modelling
}

\author{
Alexander Christian Østerskov Jensen ${ }^{1 *}$, Mikko Poikkimäki ${ }^{2}$, Anders Brostrøm $^{3}$, \\ Miikka Dal Maso ${ }^{2}$, Ole John Nielsen ${ }^{4}$, Thomas Rosenørn ${ }^{5}$, Andrew Butcher ${ }^{5}$, \\ Ismo Kalevi Koponen ${ }^{6}$, Antti Joonas Koivisto ${ }^{1}$
}

\author{
${ }^{1}$ The National Research Centre for the Working Environment, Copenhagen 2100, Denmark \\ ${ }^{2}$ Aerosol Physics, Faculty of Natural Sciences, Tampere University of Technology, FI-33101 Tampere, Finland \\ ${ }^{3}$ DTU Nanotech, Technical University of Denmark, DK-2800 Kgs. Lyngby, Denmark \\ ${ }^{4}$ Department of Chemistry, University of Copenhagen, 2100 Copenhagen, Denmark \\ ${ }^{5}$ INFUSER, 2200 Copenhagen, Denmark \\ ${ }^{6}$ FORCE Technology, 2605 Brøndby, Denmark
}

\begin{abstract}
The source rate is the single most critical input parameter in dispersion models. Determining accurate source rates from workplace processes can be challenging due to interference with work operation and poorly known dilution between the outlet of the particle generator and the measurement point. In this work, we measured the aerosol source rate in a chamber with a steady release of $\mathrm{TiO}_{2}$ particles generated by an aerosol brush generator. The number concentrations measured directly from the particle generator and in the source position near the source spanned three orders of magnitude depending on the relative location and orientation to the source. Moreover, a dispersion factor was calculated based on a single mode fit of the obtained source rates. The dispersion factor takes into account the dispersion and dilution occurring between the measurement point and the source outlet for subsequent modelling. The particle emission rates were implemented in a previously published multi-box aerosol dispersion model using a one-box layout. The modelled concentrations were compared with concentrations measured in three locations in the chamber. We found that using a dispersion factor of one, meaning that at-source dilution or dispersion was not accounted for, the modelled concentrations were 1 to 3 orders of magnitude lower than measured concentrations for all source rates except the source rates measured directly from the aerosol generator. When applying the calculated dispersion factor, thereby correcting the source rate for initial dilution and dispersion, the concentrations were within 0.5 to 2 times the measured concentrations suggesting the use of such a factor to correctly estimate the source rate, and hence the occupational exposure.
\end{abstract}

Keywords: Source measurements; Dispersion modelling; Chamber studies; Aerosol dispersion; Occupational health.

\section{INTRODUCTION}

In occupational health, airborne particles make up a significant part of personal exposures, especially in situations where high-energy processes or chemicals leading to particle formation are used (Hämeri et al., 2009). Furthermore, it has been shown that ultrafine particles are present in 60-450 times higher concentrations in industrial sectors and work environments compared to non-occupational environments (Viitanen et al., 2017). Workers are directly involved

\footnotetext{
* Corresponding author.

Tel.: +4539165312

E-mail address: alj@nrcwe.dk
}

during the release of the airborne particulate matter during many industrial processes, such as powder handling (Koivisto et al., 2012, 2015; Koponen et al., 2015), grinding and sanding activities (Koponen et al., 2011; Gomez et al., 2014; Jensen et al., 2015), laser ablation (Fonseca et al., 2015), heat treatment (Fonseca et al., 2016), plasma treatment (Viana et al., 2017), welding (Jørgensen et al., 2016), or use of chemicals (Mølgaard et al., 2015).

Air pollution causes a wide range of diseases (e.g., Thurston et al., 2017), and particulate matter, for example $\mathrm{PM}_{2.5}\left(D_{p} \leq 2.5 \mu \mathrm{m}\right)$, is considered the most harmful component for human health (Butt et al., 2017; Gakidou et al., 2017; Landrigan et al., 2017). However, in recent years there is increasing evidence that health effects are more strongly associated with fine particulate matter $\left(\mathrm{PM}_{1} ; D_{p} \leq\right.$ $1 \mu \mathrm{m})$ and ultrafine particulate matter (UFP; $D_{p} \leq 0.1 \mu \mathrm{m}$ ) 
(Seaton et al., 1995; Peters et al., 1997; Donaldson et al., 2001; Oberdörster, 2001; Nel, 2005; Politis et al., 2005; Chen et al., 2017; Stone et al., 2017).

The most reliable method to estimate exposure levels in real life work scenarios are well-performed workplace measurements. This includes mapping of concentrations with stationary instrumentation and assessing the personal exposure from the breathing zone using portable samplers and detectors (Viana et al., 2015; Asbach et al., 2017; Ding et al., 2017). Additionally, exposure assessment has been performed by means of mathematical modelling (Hemon, 1963) and is being used with increasing frequency (e.g., Hussein et al., 2015). The main reason for this is that particle measurements are challenging and expensive to perform and the analysis of the exposure levels requires expert knowledge and proper tools for statistical analysis.

In modelling, on the other hand, the accuracy depends on the characterization of the emission source, emission control efficacies, the user input variability (Hussein et al., 2011), and personnel behaviour, i.e. how sources are used and how the actual exposure occurs. A key parameter for the modelling is the source term, which in many models is the main factor defining the concentrations for the source pollutants (see e.g., Jensen et al., 2018). Thus, it is also the most critical parameter influencing modelling uncertainties, since large deviations of the source rates potentially lead to several orders of magnitude errors in the modelled concentrations. Particularly challenging are attempts to determine accurate source rates for particle sources that do not have a clearly defined associated airflow. Usually, the particle source is described with 1) worst-case assumptions (where all removed material is airborne; ECHA, 2016), 2) using the concept of a dustiness index that accounts for the material properties that affect the airborne fraction (e.g., Schneider and Jensen, 2008), 3) using a liquid saturation vapour pressure (Bilde et al., 2015), or by 4) measuring concentrations and using a mass balance equation to calculate the emission rate (Shripp et al., 2008; Koivisto et al., 2018). The source emissions are often modulated with different factors, which may not scale linearly. These factors, which attempt to capture the complexity of the aerosol emission process, include handling energy factors used for powder emissions, and transport efficiency factors or factors related to the effect of working practices or environmental conditions. However, characterising and determining the values of these factors involves several challenges and the reliability of the results is often poor. For example, one approach to estimate the mass release rates from powder processes is to use the concept of dustiness (Lidén, 2006; Schneider and Jensen, 2008), however Koivisto et al. (2015) demonstrated the limitations concerning this approach. Recently, Koivisto et al. (2017) determined that using room concentrations could form a basis for estimating the sanding process emission rates and proposed that the release rates measured from various processes could be collected in data libraries and databases for future modelling.

However, release rates from large-scale workplace processes are challenging to determine accurately because the dispersion of particles is not well known or the physical site of emission cannot be isolated from the environment without interfering with normal operation. This is because concentrations will be lower when measured near the source at a distance from the source emission than the emissions measured directly at the source due to the dispersion of the aerosol, removal by ventilation or local exhaust ventilation, coagulation, and deposition between the source and the measurement point. A strategy is to use an inverse method from the data measured in a chamber to trace back the source strength such as done by Chata et al. (2016), who implemented inverse modelling combined with CFD modelling for a steady state system. Using another approach, Jensen et al. (2018) employed a dispersion factor in the subsequent modelling of the room concentrations to take into account the dispersion and dilution between the source outlet and the source measurement point. They found that the dispersion factor was needed to accurately predict the concentrations in the chamber. However, while the dispersion factor improves modelling results, the connection between the dispersion factor and the location of the source measurement point remains poorly understood, which limits its applicability.

In this work, we investigate the impact of direction and measurement distance from the source with a jet-like emission flow originating from an aerosol dispersion brush generator. The source simulates a highly directional flow similar to the release occurring from spraying of chemicals with an airgun, propellant or pump spray, liquid flame spray, leakage from pressurised systems, or grinding, sanding or other similar high energy processes. The outlet of the brush generator was positioned in seven different orientations with respect to the instruments' sampling inlets. Reference concentrations were measured directly from the outlet of the particle generator, which corresponds to the release rate. The measured size distributions were fitted with single log-normal mode distributions to estimate the dispersion factors. The obtained dispersion factors were verified by modelling of the chamber particle number concentrations, and comparing the modelled concentrations with the measured concentrations. For modelling, the chamber was assumed to be a single well-mixed box. This study, furthermore, shows the uncertainties of using the measured source rates from a jet-like emission in the model by comparing the modelled and the measured particle number concentrations.

\section{MATERIALS AND METHODS}

\section{Aerosol Generation}

A PALAS aerosol brush generator (RBG 1000, Karlsruhe, Germany) was used for dispersing nano-sized $\mathrm{TiO}_{2}$ (M111 UV-nanotitan, Kemira, Finland). The $\mathrm{TiO}_{2}$ consist of agglomerates with a primary particle size of $14 \mathrm{~nm}$ according to TEM analysis by Vippola et al. (2009). The $1 \mathrm{~cm}$ in diameter canister of the brush generator was filled with $2 \mathrm{~cm}$ to $2.6 \mathrm{~cm}$ of $\mathrm{TiO}_{2}$ to accommodate 360 to $480 \mathrm{~s}$ of active source release. The brush was set to $675-680 \mathrm{rpm}$ with a feed speed of $20.0 \mathrm{~cm} \mathrm{~h}^{-1}$. The flow rate was measured to be $50 \mathrm{~L} \mathrm{~min}^{-1}$ at 1.2 bar pre-pressure. When 
the canister was empty, the rotation of the brush turned off automatically.

\section{Experimental Setup}

The chamber measurements were carried out in a custom made chamber. The chamber was made from plastic sheets suspended in a metal frame scaffold. The dimensions of the chamber were $5.0 \mathrm{~m} \times 3.0 \mathrm{~m} \times 2.9 \mathrm{~m}$ with a total volume of $43.5 \mathrm{~m}^{3}$. The chamber was ventilated at a constant air exchange rate (AER) of $5 \mathrm{~h}^{-1}$ via filtered air. The ventilation air inlet was at the top of the chamber and the outlet was in the bottom of the chamber in the opposite corner located at the same wall (Fig. 1). No additional mechanical mixing was used inside the chamber. Between the experiments the chamber was flushed to reach a particle number concentration lower than $2000 \mathrm{~cm}^{-3}$.

Inside the chamber, particle concentrations were monitored using aerosol online instruments (Table 1) located near the source position (source), in the near field (NF), and in far field 1 (FF1) and far field 2 (FF2). The experimental setup, as well as, positioning of instruments is shown in Fig. 1. The instruments measuring at the source were placed outside the chamber and concentrations were sampled using $6 \mathrm{~mm}$ copper tubes. Concentrations measured with particle sizers were corrected for diffusion losses according to Cheng (2001).

Samples for electron microscopy were collected in the FF1 location using a three-stage cascade impactor, where each stage was equipped with a Nickel TEM grid with lacey carbon substrate (Ted Pella). A diaphragm gas pump (NMP 830, KNF Neuberger, Germany) was used, resulting in a flowrate of $0.76 \mathrm{~L} \mathrm{~min}^{-1}$ and theoretical cut-off diameters of $1.37,0.59$, and $0.055 \mu \mathrm{m}$ for the three stages respectively. The electron microscopy samples were imaged with a Tecnai T20 G2 (FEI, The Netherlands) operated at $200 \mathrm{kV}$ and magnifications varying between $20 \mathrm{k}$ and $100 \mathrm{k}$, corresponding to resolutions from approximately 0.5 to $4 \mathrm{~nm}$ per pixel. A few high-resolution images, as well as energy dispersion $\mathrm{x}$-ray spectroscopy analysis was performed on selected particles to verify their composition. Images were analysed using the commercially available software ImageJ, where segmentation was performed using either global or adaptive thresholding techniques, depending on the state of the substrate.

The effect of the source's spatial position and flow direction was evaluated by moving the brush generator

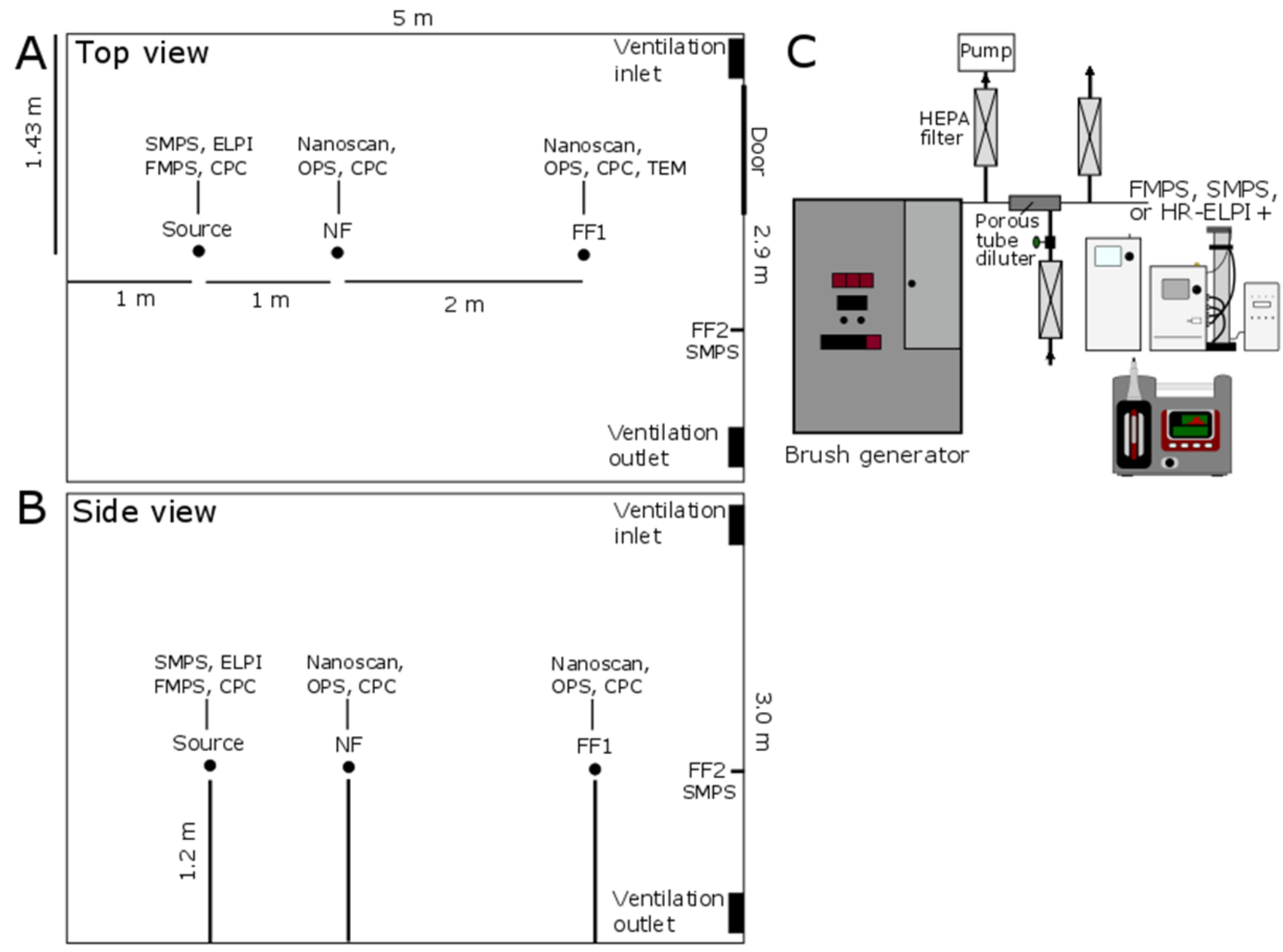

Fig. 1. The location of the measurement positions as (A) top view and (B) side view of the chamber, along with instruments present in each location, and position of the ventilation inlet (top right corner) and exhaust (bottom left corner). The measurement set-up for the reference concentrations (C). 


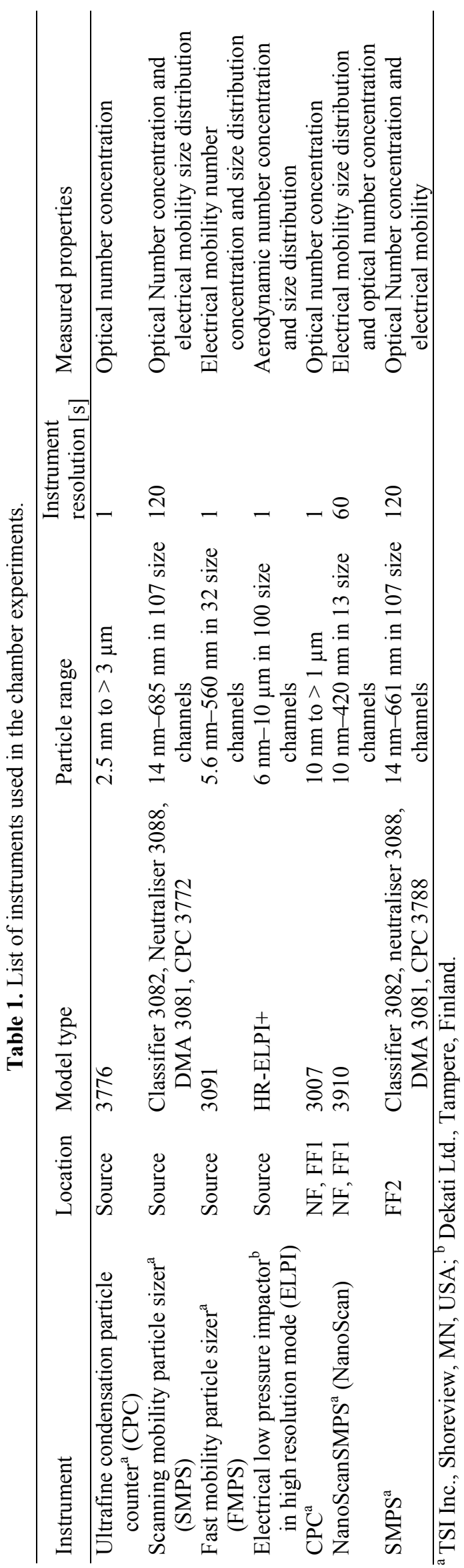

outlet and maintaining the instrument sampling position stationary. Seven different source orientations, labelled \#1 to \#7, were evaluated (Fig. 2(a)). For orientation \#1, the outlet was positioned $5 \mathrm{~cm}$ from the source measurement point with the flow direction directly towards the inlet leading to the instruments. Orientation \#2 was located 8 $\mathrm{cm}$ from the source measurement point directed towards the source and with a perpendicular flow direction. Orientation \#3 was $15 \mathrm{~cm}$ from the source point and similarly pointed directly at the source measurement point. Orientations \#4 and \#5 were located on the top of and below the copper tubes leading to the instruments, respectively, and pointed parallel to the inlet tubes with an opposing flow direction compared to the instrument flow. Orientation \#6 was located $1.5 \mathrm{~cm}$ in front of the source measurement point with a perpendicular flow direction. Orientation \#7 was pointed directly away from the source measurement point $30 \mathrm{~cm}$ below it.

Reference concentrations were measured directly from the brush generator. Due to high concentrations from the brush generator the particles were diluted prior to measuring with SMPS, ELPI, or FMPS. A pump was used to remove $49 \mathrm{~L} \mathrm{~min}^{-1}$ of the air from the brush generator, while $1 \mathrm{~L} \mathrm{~min}^{-1}$ was directed to a porous tube diluter (Lyyränen et al. 2004) to ensure homogeneous dilution and diluted with HEPA filtered air (Fig. 1(c)). The reference concentrations were measured one at a time and diluted with a factor of 85 , 26, and 14 for the FMPS, ELPI, and SMPS, respectively.

The size distributions from the measurements at the source position in the chamber, as well as, the reference concentrations were fitted to single-mode distributions using the method described by Hussein et al. (2005).

\section{Modelling}

The chamber concentration levels were modelled by using a modified version of the multi-compartment model presented in Jensen et al. (2018). The chamber was assumed to be a single well-mixed box with ventilation flow rate $\mathrm{Q}$ of $0.06 \mathrm{~m}^{3} \mathrm{~s}^{-1}$. The coagulation was calculated according to Guichard et al. (2014), which allowed for better prediction of coagulation for particles larger than $100 \mathrm{~nm}$ compared to the previous algorithm, which was based on pure Brownian coagulation, the calculated self-coagulation coefficients are shown in Fig. S1, Supporting information. The deposition rates were calculated according to Lai and Nazaroff (2000). For the deposition, we assumed a particle density of $1 \mathrm{~g} \mathrm{~cm}^{-3}$ and a friction velocity of $1 \mathrm{~cm} \mathrm{~s}^{-1}$.

For a measured source, the source rate $\mathrm{S}_{\mathrm{i}}$ is defined as

$\mathrm{S}_{\mathrm{i}}=\mathrm{C}_{\mathrm{s}, \mathrm{i}} \cdot \mathrm{DF}_{\mathrm{N}} \cdot \mathrm{Q}_{\mathrm{s}}$

where $\mathrm{C}_{\mathrm{s}, \mathrm{i}}\left[\mathrm{m}^{-3}\right]$ is the measured concentration in size bin $\mathrm{i}$,

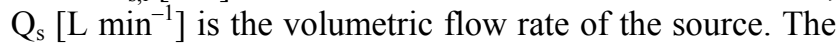
dispersion factor, $\mathrm{DF}_{\mathrm{N}}$, is a fitting factor to take into account the dispersion and dilution occurring between the measurement point and the source outlet during the measurement, where a dispersion factor of 1 meaning that there is no dispersion or dilution. The dispersion factor was calculated using the fitted source modes according to Eq. (2). 


$$
\mathrm{DF}_{\mathrm{N}}=\frac{\mathrm{N}_{\text {fitted source reference }}}{\mathrm{N}_{\text {fitted source measured }}}
$$

For validation of the modelled concentrations, we used the concentrations measured in the NF, FF1, and FF2. The concentrations measured with the NanoScans and CPCs during all seven experiments were combined to single datasets of total average concentrations and standard deviations. The combined standard deviation of the dataset, S, was calculated using Eq. (3) (Headrick, 2010).

$$
\begin{aligned}
\mathrm{S}^{2} & =\left(\mathrm{n}_{\mathrm{NF}}^{2} \mathrm{~s}_{\mathrm{NF}}^{2}+\mathrm{n}_{\mathrm{FF}}^{2} \mathrm{~s}_{\mathrm{FF}}^{2}-\mathrm{n}_{\mathrm{FF}} \mathrm{s}_{\mathrm{NF}}^{2}-\mathrm{n}_{\mathrm{FF}} \mathrm{s}_{\mathrm{FF}}^{2}-\mathrm{n}_{\mathrm{NF}} \mathrm{s}_{\mathrm{NF}}^{2}-\mathrm{n}_{\mathrm{NF}} \mathrm{s}_{\mathrm{FF}}^{2}\right. \\
& \left.+\mathrm{n}_{\mathrm{NF}} \mathrm{n}_{\mathrm{FF}} \mathrm{s}_{\mathrm{NF}}^{2}+\mathrm{n}_{\mathrm{NF}} \mathrm{n}_{\mathrm{FF}} \mathrm{s}_{\mathrm{FF}}^{2}+\mathrm{n}_{\mathrm{NF}} \mathrm{n}_{\mathrm{FF}}\left(\overline{\mathrm{C}}_{\mathrm{NF}}-\overline{\mathrm{C}}_{\mathrm{FF}}\right)^{2}\right) \\
& /\left(\left(\mathrm{n}_{\mathrm{NF}}+\mathrm{n}_{\mathrm{FF}}-1\right)\left(\mathrm{n}_{\mathrm{NF}}+\mathrm{n}_{\mathrm{FF}}\right)\right)
\end{aligned}
$$

where $\mathrm{n}$ is the number of experiments, $\mathrm{s}$ is the standard deviation, and $\mathrm{C}$ is the average concentration.

\section{RESULTS}

\section{Source Concentrations}

The total number concentrations for the reference concentrations and the source orientations \#1 to \#7 measured in the chamber by the FMPS and ELPI are shown in Fig. 2(b). The source concentraions measured by the SMPS and CPC are shown in Fig. S2, supporting information for the reference concentrations, the release was shorter than during the chamber experiments to avoid overloading the instruments. The reference concentrations gave rise to the highest measured number concentrations, as expected, with peak number concentrations measured by the ELPI of up to $6 \cdot 10^{6} \mathrm{~cm}^{-3}$. This was significantly higher than measured during the chamber experiments. For orientation $\# 1$, where there was the shortest distance between the outlet of the aerosol generator and the measurement point, as well as the most favourable flow direction, the concentrations were one order of magnitude lower than the reference concentrations at a maximum of $6 \cdot 10^{5} \mathrm{~cm}^{-3}$ measured by the FMPS. For both orientations $\# 1$ and $\# 2$, the measured concentrations were 10 to 50 times higher than for any of the other orientations. For orientation \#3, the datasets for the SMPS and FMPS were incomplete due to instrumental errors, and therefore not used in the subsequent modelling, however both SMPS and FMPS recorded concentrations higher than for orientations \#4 to \#7. It is reasonable to assume that the higher concentrations in orientations \#1, \#2, and \#3 were due to flow from the aerosol generator being directed directly towards the source measurement point. Generally, during each experiment, the FMPS produced the highest total number concentration readings (except for orientation \#2), followed by the ELPI, while the SMPS and CPC measured similar total number concentrations, which were lower than concentrations measured by both the ELPI and the FMPS due to differences in method of operation. For orientation \#2 the tube leading to the FMPS was slightly
A

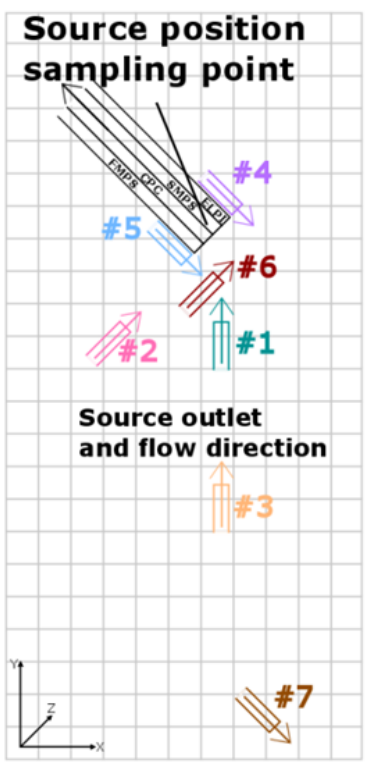

B

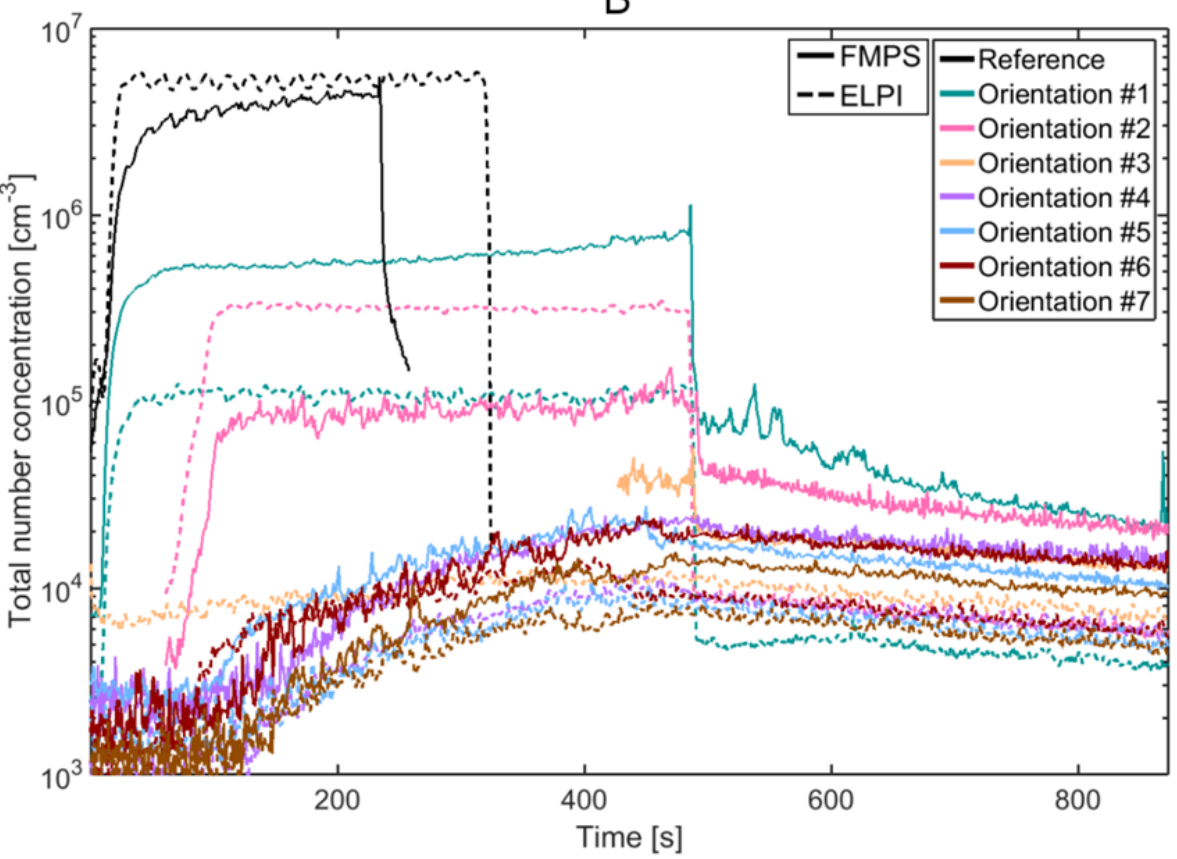

Fig. 2. (A) Schematic of the source measurement position and orientation and relative distances in the $\mathrm{X}$ and $\mathrm{Y}$ plane of the outlet of the brush generator. The positions in the $\mathrm{Z}$ axis plane were always kept the same. Gridlines are shown with $2 \mathrm{~cm}$ spacing. (B) Total number concentrations of the reference concentrations and as measured in the source position in orientations \#1 to \#7 using FMPS and ELPI. Different orientations and instruments are noted in colours and line styles, respectively. 
misaligned and thus the lower concentrations in orientation \#2. During the experiment orientation \#7, where the source flow direction was directly away from the source measurement position, the total number concentrations were the lowest measured in the source position.

The geometric mean diameter (GMD), geometric standard deviation (GSD), and total number concentration $(\mathrm{N})$ for the log-normally fitted single mode distributions are shown in Table 2. The GMD were consistent for each instrument with average geometric mean diameters based on the chamber experiments of $188.1 \pm 5.1 \mathrm{~nm}$ (mobility diameter), $421.2 \pm 20.7 \mathrm{~nm}$ (aerodynamic diameter), and $259.0 \pm$ $5.5 \mathrm{~nm}$ (mobility diameter) for the FMPS, ELPI, and SMPS, respectively. For the SMPS, the fitted mode was based on few data points compared with the other instruments due to a time resolution of $120 \mathrm{~s}$. The geometric mean diameters of the reference concentrations measured by the SMPS were significantly higher than measured in the chamber, while for the ELPI only the first 120 seconds after the release initiated were used for fitting of the mode due to material build-up on the impactor plates and overloading the instrument resulting in overestimation of the GMD. Distributions were found to have a GSD in the range of 1.4-2.1. For both FMPS and SMPS, the fitted N was found to be decreasing from orientation \#1 to \# 7 with \#4 to \#6 almost identical. However, for the ELPI in orientations \#1 to $\# 3$, the $\mathrm{N}$ for orientation $\# 2$ is significantly larger than for orientation \#1 and $\mathrm{N}$ for orientation \#3 lower than for orientations \#2 and \#4, respectively. The size distributions measured by the NanoScans were fitted to a single mode distribution with GMD $=140 \mathrm{~nm}, \mathrm{GSD}=1.6$, and $\mathrm{N}=$ $2.6 \cdot 10^{4} \mathrm{~cm}^{-3}$. For the FF2 SMPS, the fitted mode was $\mathrm{GMD}=265 \mathrm{~nm}, \mathrm{GSD}=1.9$, and $\mathrm{N}=8.3 \cdot 10^{4} \mathrm{~cm}^{-3}$. The distributions are shown in Fig. S3, supporting information.

\section{Comparison of Measured and Modelled Concentrations}

$\mathrm{C}_{\mathrm{s}, \mathrm{i}}$ for the reference concentrations was constructed to last for a total duration of $420 \mathrm{~s}$ by using the average number concentration and size distribution that was measured during the first $120 \mathrm{~s}$ after the initial increase in concentration (Fig. S4, supporting information). Due to the incomplete source data from orientation \#3 only the ELPI source rates were used for the modelling. When using $\mathrm{DF}_{\mathrm{N}}$ $=1$ for all orientations, the modelled concentrations were underestimating the measured concentrations, except when using the reference concentrations (Fig. 3(a)). The best fit using sources measured in the chamber was found for orientations \#1, where the root mean squared logarithmic error (RMSLE) of the measured and modelled concentrations were 0.37 between 1.65 (Table 3 ). For orientation \#2, the RMSLE was 0.68 to 1.69 , whereas for orientations from \#3 to \#7 the RMSLE was found to be 1.87 to 2.83 depending on the compared instruments. The fit was generally better when compared with the measured SMPS and CPC concentrations as the total number concentrations were lower than the total number concentration that were measured by the NanoScan.

The dispersion factor was calculated using Eq. (2) to be between 6 , for orientation \#1 and using FMPS concentrations, to 945 , in orientation \#7 for the ELPI (Table 2). When the calculated dispersion factor was applied in the modelling, the modelled concentrations for all orientations using the FMPS and ELPI concentrations as $\mathrm{C}_{\mathrm{s}, \mathrm{i}}$, except in orientation $\# 3$, were found to be within the combined standard deviation of the NanoScan concentrations (Fig. 3(b)), but overestimate the CPC and FF2 SMPS concentrations. Using the calculated dispersion factor the modelled concentrations improved in all cases with RMSLE between 0.04 and 0.97 . When using the SMPS source concentrations for the $\mathrm{C}_{\mathrm{s}, \mathrm{i}}$, the modelled concentrations the best fit was found when comparing these with the concentrations measured by FF2 SMPS and CPC. Here the RMSLE was found to be between 0.04 and 0.35 , whereas when compared with the average concentration measured by the NanoScans the RMSLE was 0.60 to 0.72 . Similarly, the RMSLE was lower when comparing the modelled concentrations based

Table 2. Source size distributions fitted to single mode distributions defined by the geometric mean diameter (GMD), geometric standard deviation (GSD), and number concentration $(\mathrm{N})$. The calculated dispersion factor $\left(\mathrm{DF}_{\mathrm{N}}\right)$ for each orientation.

\begin{tabular}{|c|c|c|c|c|c|c|c|c|c|}
\hline \multicolumn{2}{|c|}{ Orientation } & $\mathrm{C}_{\mathrm{R}}$ & $\# 1$ & $\# 2$ & $\# 3$ & $\# 4$ & $\# 5$ & $\# 6$ & $\# 7$ \\
\hline \multicolumn{2}{|c|}{ Flow direction } & Online & $\begin{array}{l}5 \mathrm{~cm} \\
\text { towards }\end{array}$ & $\begin{array}{l}8 \mathrm{~cm} \\
\text { Perpendicular }\end{array}$ & $\begin{array}{l}15 \mathrm{~cm} \\
\text { towards }\end{array}$ & $\begin{array}{l}\text { Parallel } \\
\text { away }\end{array}$ & $\begin{array}{l}\text { Parallel } \\
\text { away }\end{array}$ & $\begin{array}{l}1.5 \mathrm{~cm} \\
\text { in front }\end{array}$ & $\begin{array}{l}30 \mathrm{~cm} \\
\text { away }\end{array}$ \\
\hline \multirow[t]{4}{*}{ FMPS } & GMD [nm] & 176.1 & 184.5 & 196.1 & 193.1 & 190.2 & 185.9 & 185.9 & 181.6 \\
\hline & GSD & 1.4 & 1.4 & 1.4 & 1.4 & 1.4 & 1.4 & 1.4 & 1.4 \\
\hline & $\mathrm{N}\left[\mathrm{cm}^{-3}\right] \times 10^{3}$ & 3650 & 577 & 85 & 31 & 17 & 17 & 15 & 11 \\
\hline & $\mathrm{DF}_{\mathrm{N}}$ & 1 & 6 & 43 & 118 & 215 & 215 & 243 & 332 \\
\hline \multirow[t]{4}{*}{ ELPI } & GMD [nm] & 421.0 & 409.8 & 403.6 & 391.4 & 422.6 & 449.4 & 432.5 & 439.1 \\
\hline & GSD & 2.1 & 2.1 & 1.8 & 2.1 & 1.8 & 1.8 & 1.7 & 1.8 \\
\hline & $\mathrm{N}\left[\mathrm{cm}^{-3}\right] \times 10^{3}$ & 4730 & 106 & 297 & 5 & 8 & 7 & 9 & 5 \\
\hline & $\mathrm{DF}_{\mathrm{N}}$ & 1 & 45 & 16 & 945 & 591 & 675 & 525 & 945 \\
\hline \multirow[t]{4}{*}{ SMPS } & GMD [nm] & 299 & N.D. & 260.6 & 264.6 & 254.6 & 250.7 & 258.6 & 264.6 \\
\hline & GSD & 2.0 & N.D. & 1.9 & 2.1 & 2.0 & 1.9 & 1.9 & 2.0 \\
\hline & $\mathrm{N}\left[\mathrm{cm}^{-3}\right] \times 10^{3}$ & 1450 & N.D. & 95 & 12 & 10 & 9 & 10 & 7 \\
\hline & $\mathrm{DF}_{\mathrm{N}}$ & 1 & N.D. & 15 & 121 & 145 & 161 & 145 & 207 \\
\hline
\end{tabular}

N.D. no data. 

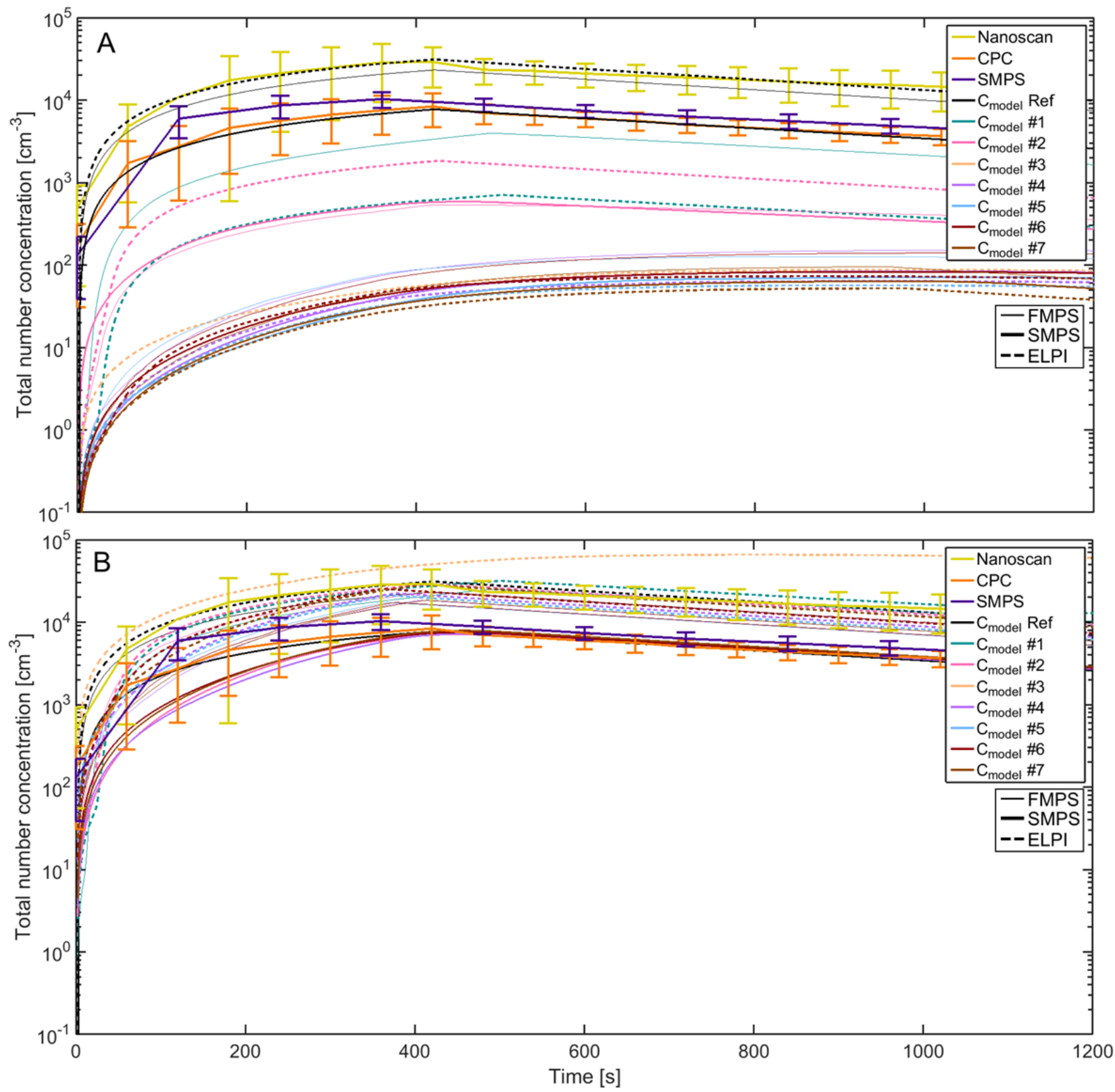

Fig. 3. Averaged total number concentrations measured during the seven chamber experiments with standard deviations and modelled concentrations using the reference concentrations or source concentrations measured in orientations \#1 through \#7, and using (A) a dispersion factor of 1 for all orientations or (B) using the dispersion factor, DF $F_{\mathrm{N}}$, from Table 1. Colours indicating the source orientations are marked with different line styles to indicate the instrument that has been used for $\mathrm{C}_{\mathrm{s}, \mathrm{i}}$.

on the source rates measured by the ELPI or the FMPS with the average concentration measured by the NanoScans. Here the RMSLE was between 0.05 and 0.37 , whereas when compared with the concentrations measured by the FF2 SMPS and the CPC the RMSLE was between 0.20 and 0.97 (Table 3).

\section{Electron Microscopy Analysis of the $\mathrm{TiO}_{2}$}

The TEM grids from the first two stages of the impactor corresponding to cut-off diameters of $1.37 \mu \mathrm{m}$ and $0.59 \mu \mathrm{m}$ contained only very few micrometre-sized agglomerated particles. Particles were made up from titanium-containing elongated crystalline primary particles with sizes of 5-15 nm. The lowest stage with a cut-off diameter of $0.055 \mu \mathrm{m}$, however, was dominated by sub $100 \mathrm{~nm}$ particles, consisting of 5-20 primary particles each, whereas, larger agglomerates were observed to be between $200 \mathrm{~nm}$ and $500 \mathrm{~nm}$ in diameter (Fig. S5, supporting information).

\section{DISCUSSION}

Our experimental and modelling results clearly show that the measurement position in relation to a directional source needs to be considered carefully both for 
Table 3. Calculated root mean squared logarithmic error of the measured and modelled concentrations. The instrument that the source is based on is indicated.

\begin{tabular}{|c|c|c|c|c|c|c|c|c|c|c|}
\hline & \multirow{2}{*}{$\mathrm{C}_{\text {measured }}$} & \multirow{2}{*}{$\mathrm{C}_{\text {modelled }}$} & \multicolumn{8}{|c|}{ Orientation } \\
\hline & & & $\mathrm{C}_{\text {reference }}$ & $\# 1$ & $\# 2$ & $\# 3$ & $\# 4$ & $\# 5$ & $\# 6$ & $\# 7$ \\
\hline \multirow[t]{9}{*}{$\mathrm{DF}_{\mathrm{N}}=1$} & \multirow[t]{3}{*}{$\mathrm{C}_{\text {NanoScan }}^{\dagger}$} & $\mathrm{C}_{\text {model FMPS }}$ & 0.13 & 0.91 & 1.69 & N.D. & 2.40 & 2.41 & 2.44 & 2.60 \\
\hline & & $\mathrm{C}_{\text {model ELPI }}$ & 0.05 & 1.65 & 1.24 & 2.53 & 2.71 & 2.77 & 2.63 & 2.83 \\
\hline & & $\mathrm{C}_{\text {model SMPS }}$ & 0.60 & N.D. & 1.68 & N.D. & 2.66 & 2.73 & 2.62 & 2.76 \\
\hline & \multirow[t]{3}{*}{$\mathrm{C}_{\mathrm{SMPS}}{ }^{*}$} & $\mathrm{C}_{\text {model FMPS }}$ & 0.32 & 0.48 & 1.25 & N.D. & 1.94 & 1.95 & 1.98 & 2.15 \\
\hline & & $\mathrm{C}_{\text {model ELPI }}$ & 0.45 & 1.20 & 0.80 & 2.08 & 2.25 & 2.31 & 2.17 & 2.37 \\
\hline & & $\mathrm{C}_{\text {model SMPS }}$ & 0.18 & N.D. & 1.24 & N.D. & 2.20 & 2.28 & 2.16 & 2.30 \\
\hline & \multirow[t]{3}{*}{$\mathrm{C}_{\mathrm{CPC}}^{\dagger}$} & $\mathrm{C}_{\text {model FMPS }}$ & 0.45 & 0.37 & 1.14 & N.D. & 1.87 & 1.87 & 1.91 & 2.07 \\
\hline & & $\mathrm{C}_{\text {model ELPI }}$ & 0.57 & 1.09 & 0.68 & 1.99 & 2.17 & 2.23 & 2.09 & 2.29 \\
\hline & & $\mathrm{C}_{\text {model SMPS }}$ & 0.04 & N.D. & 1.12 & N.D. & 2.13 & 2.20 & 2.08 & 2.22 \\
\hline \multirow[t]{9}{*}{ Calculated $\mathrm{DF}_{\mathrm{N}}$} & \multirow[t]{3}{*}{$\mathrm{C}_{\text {NanoScan }}^{\dagger}$} & $\mathrm{C}_{\text {model FMPS }}$ & 0.13 & 0.16 & 0.17 & N.D. & 0.37 & 0.34 & 0.36 & 0.35 \\
\hline & & $\mathrm{C}_{\text {model ELPI }}$ & 0.05 & 0.12 & 0.08 & 0.45 & 0.26 & 0.28 & 0.17 & 0.18 \\
\hline & & $\mathrm{C}_{\text {model SMPS }}$ & 0.60 & N.D. & 0.71 & N.D. & 0.72 & 0.67 & 0.67 & 0.67 \\
\hline & \multirow[t]{3}{*}{$\mathrm{C}_{\mathrm{SMPS}}{ }^{*}$} & $\mathrm{C}_{\text {model FMPS }}$ & 0.32 & 0.39 & 0.31 & N.D. & 0.26 & 0.20 & 0.21 & 0.25 \\
\hline & & $\mathrm{C}_{\text {model ELPI }}$ & 0.45 & 0.48 & 0.41 & 0.89 & 0.29 & 0.26 & 0.32 & 0.38 \\
\hline & & $\mathrm{C}_{\text {model SMPS }}$ & 0.18 & N.D. & 0.32 & N.D. & 0.34 & 0.35 & 0.28 & 0.29 \\
\hline & \multirow[t]{3}{*}{$\mathrm{C}_{\mathrm{CPC}}^{\dagger}$} & $\mathrm{C}_{\text {model FMPS }}$ & 0.45 & 0.48 & 0.42 & N.D. & 0.31 & 0.27 & 0.28 & 0.31 \\
\hline & & $\mathrm{C}_{\text {model ELPI }}$ & 0.57 & 0.58 & 0.53 & 0.97 & 0.37 & 0.34 & 0.43 & 0.48 \\
\hline & & $\mathrm{C}_{\text {model SMPS }}$ & 0.04 & N.D. & 0.24 & N.D. & 0.25 & 0.28 & 0.19 & 0.21 \\
\hline
\end{tabular}

${ }^{\dagger}$ Average of NF and FF1 positions, ${ }^{\dagger} \mathrm{FF} 2$ position, N.D. No data.

interpretation of measured results, as well as using them as model input. For orientations where the jet is not pointing directly towards the source measurement point, the concentrations measured in the source position were similar to the concentrations measured in the chamber. Closer proximity to the source had only little effect on the total number concentrations if the flow was not pointed towards the measurement position as the source generator used here produced a jet-like stream. The resulting source flow has a high directionality and high sensitivity to small adjustments of the outlet flow direction. For a round jet, the aerosol velocity at the exit is initially a top hat distribution profile. After the zone of flow establishment, which is typically defined as $\mathrm{K}_{1} \cdot \mathrm{D}$ from the virtual origin, where $\mathrm{K}_{1}$ is an experimentally determined constant and $\mathrm{D}$ is the diameter of the jet exit, the time-smoothed velocity and concentration profile changes into a Gaussian distribution that broadens with distance (Fisher et al., 1979; Or et al., 2011). The axial velocity and concentration decreases as a function of one over the distance from the exit after the initial zone of flow establishing (Albertson et al., 1948; Pope, 2000). The GMD of the particles dispersed were between 188 and $421 \mathrm{~nm}$ depending on the instrument. Particles in this range are primarily affected by the drag force of the carrier gas in the jet, while the effect of diffusion at the centreline is limited initially due to the initial high velocity. Along the edges of the carrier gas, the velocity of the gas is lower due to the bell-shaped velocity profile and mixing of the particles to the chamber air is caused mainly by shear turbulence and diffusion. This causes a highly directional transport of the released pollutants until the velocity at the centre jet approaches the velocity of the chamber air, with the centre of the jet having the highest concentrations of aerosols. Furthermore, the cross-sectional concentration profile is narrower for the particles than for the carrier gas (Fan et al., 1997), which increases the sensitivity further to the radial position in the jet. We assume that due to the concentration gradient at the centreline of the jet cone and since the inlets to the FMPS and ELPI measuring at the source position are at slightly different distances ( $2 \mathrm{~cm}$ apart) to the brush generator outlet for orientations \#1 and \#3, this leads to differences in the measured source concentrations between instruments in these source orientations. For the orientations \#4 to \#7 these positions are less sensitive to the exact position of the inlet of the instruments as concentration gradient is not as steep as in the centreline of the jet.

Furthermore, analysis of the measurements showed that for the fitted size distribution, the GMD for the FMPS and NanoScan were lower than for the SMPS despite both are based on the mobility of the particle for detection. This is because the FMPS and NanoScan underestimate the particles sizes larger than $200 \mathrm{~nm}$ and at the same time overestimates the number concentrations (Levin et al., 2015, Fonseca et al., 2016). As the analysis by transmission electron microscopy showed, the dispersed $\mathrm{TiO} 2$ are agglomerated particles with a size of around less than 100 $\mathrm{nm}$ with larger agglomerates up to $500 \mathrm{~nm}$, which is in the range where the FMPS and NanoScan measure incorrect concentrations. This means that concentrations and size distributions of the FMPS and the NanoScan are better inter-compared than other instruments as they measure similar properties and size ranges.

Based on modelling results, we show that by using measured chamber concentrations without correction as an input for the source term in the dispersion model, the concentrations in the chamber are underestimated by 1 to 3 orders of magnitude. This means that using source rate 
measurements from monitoring of work carried out with a highly directional flow - without correcting for the nearsource dispersion - and then using the results for exposure assessment modelling will often underestimate the concentrations and therefore the exposure assessment of the workers carrying out the work. The underestimation of the modelled total number concentration could be taken into account by employing a dispersion factor on the source concentration similar as also shown in Jensen et al. (2018).

Applying the dispersion factor for the measured source in the model caused the modelled concentrations to be within the standard deviation of the concentrations measured by the NanoScan. Modelled concentrations using both the FMPS and ELPI source rates were higher than what was measured by the SMPS and the CPC. Fitted GMD for the reference concentrations were lower than for the measured source in the chamber, but despite this, the estimate of the dispersion factor produced more accurate modelled concentrations compared with a situation when a dispersion factor of one was applied. In general, source concentrations measured in other places than in very close proximity to the source outlet with the jet pointing directly towards the measurement position were not representative of the source release rates from the particle generator and had to be adjusted by dispersion factors as high as 945. During the time between pollutant release and measurement at the source position the particle size distribution is not expected to change significantly as coagulation and deposition rates are low compared with the mixing. Thus a constant dispersion factor can be applied to the source term. However, a problem might arise from measuring in close proximity of the source, since samplers with high volume flow could act as unintended local exhaust ventilation by removing particles from the source causing lower concentrations in the rest of the chamber. As expected, the modelled concentrations based on the SMPS source concentrations compared better with the concentrations measured by the SMPS in the chamber, while the modelled concentrations based on the FMPS source concentrations compared better with the measured NanoScan concentrations due to similarities in measurement range and detection method. Applying the dispersion factor greatly improves the quality of the modelled concentrations and provides a better fit to the measured concentrations.

\section{CONCLUSION}

In the presented work, we show the effect of inlet distance and direction on source measurements by using a brush generator as a highly directional aerosol source. Based on chamber experiments with chamber concentrations being monitored in three different positions and a source position near the source, we found that the measured source rate is highly dependent on the experimental setup as well as the position and orientation of the sampling inlet relative to the source. The source rate can be considerably underestimated even at short distances, e.g., $15 \mathrm{~cm}$, from the point source. This underestimation is worse for orientations with a flow away from the source measurement position even if the distance is less than $1 \mathrm{~cm}$ due to the jet-like appearance of the source flow. In the worst case, if the aerosol inlet flow is opposite to the directional source flow, the concentrations directly at the source position are similar as measured in the far-field chamber positions. This results in underestimation of the source rates compared to the reference source rates. The modelled concentrations, using the reference source rates, were in good agreement with the concentrations measured in the chamber. Hence, we suggest that the source rate should be measured separately with a closed/sealed tube with a known volumetric flow rate. In this way, the measured concentration can be converted to a source rate by multiplying the measured concentrations with the flow rate. In this method, the source needs to be isolated for separate source rate measurement. However, this is not always possible, and, in such case, the sampling inlet should be located as close to the source as possible in line with flow from the source to minimize effects of dilution and dispersion. Furthermore, in a jet-like source, the source rate should be measured as close as possible to the middle of the flow streamline inside the zone of flow establishment. In the present work, an appropriate dispersion factor could be used when modelling chamber concentrations and was successfully estimated here based on fitted modes from the measured and the reference concentrations. We showed that a successfully determined dispersion factor can improve the modelling results to match observed concentrations even in the case where the source position was misaligned as for the FMPS in orientation \#2. Determining the correct dispersion factor for the model is, however, not straightforward without reference concentrations, highlighting the need for further examination of the process of determining this parameter.

\section{ACKNOWLEDGEMENTS}

We thank Infuser A/S for providing facilities and lending instrumentation used in this study. The Danish Centre for Nanosafety II provided funding and M.P. acknowledges the TUT graduate school for financial support.

\section{CONFLICT OF INTEREST}

The authors declare no conflict of interest.

\section{SUPPLEMENTARY MATERIAL}

Supplementary data associated with this article can be found in the online version at http://www.aaqr.org.

\section{REFERENCES}

Albertson, M.L., Dai, Y.B., Jensen, R.A. and Rouse, H. (1948). Diffusion of submerged jets. Proc. Am. Soc. Civil Eng. 74: 1571-1596.

Asbach, C., Alexander, C., Clavaguera, S., Dahmann, D., Dozol, H., Faure, B., Fierz, M., Fontana, L., Iavicoli, I., Kaminski, H., MacCalman, L., Meyer-Plath, A., Simonow, 
B., van Tongeren, M. and Todea, A.M. (2017). Review of measurement techniques and methods for assessing personal exposure to airborne nanomaterials in workplaces. Sci. Total Environ. 603-604: 793-806.

Bilde, M., Barsanti, K., Booth, M., Cappa, C.D., Donahue, N.M., Emanuelsson, E.U., McFiggans, G., Krieger, U.K., Marcolli, C., Topping, D., Ziemann, P., Barley, M., Clegg, S., Dennis-Smither, B., Hallquist, M., Hallquist, Å.M., Khlystov, A., Kulmala, M., Mogensen, D., Percival, C.J., Pope, F., Reid, J.P., Ribeiro da Silva, M.A., Rosenoern, T., Salo, K., Soonsin, V.P., Yli-Juuti, T., Prisle, N.L., Pagels, J., Rarey, J., Zardini, A.A. and Riipinen, I. (2015). Saturation vapor pressures and transition enthalpies of low-volatility organic molecules of atmospheric relevance: From dicarboxylic acids to complex mixtures. Chem. Rev. 115: 4115-4156.

Butt, E.W., Turnock, S.T., Rigby, R., Reddington, C.L., Yoshioka, M., Johnson, J.S., Regayre, L.A., Pringle, K.J., Mann, G.W. and Spracklen, D.V. (2017). Global and regional trends in particulate air pollution and attributable health burden over the past 50 years. Environ. Res. Lett. 12: 104017.

Chata, F., Belut, E., Keller, F.X. and Taniere, A. (2016). Particulate pollutant source evaluation using an inverse method under steady-state conditions. J. Occup. Environ. Hyg. 13: 223-233.

Chen, G., Li, S., Zhang, Y., Zhang, W., Li, D., Wei, X., He, Y., Bell, M.L., Williams, G., Marks, G.B., Jalaludin, B., Abramson, M.J. and Guo, Y. (2017). Effects of ambient $\mathrm{PM}_{1}$ air pollution on daily emergency hospital visits in China: An epidemiological study. Lancet Planet. Health 1: e221-e229.

Cheng, Y.S. (2001). Condensation detection and diffusion size separation techniques. In Aerosol measurements: Principles, techniques and applications, Baron, P.A. and Willeke, K. (Eds.), Wiley-Interscience, New York, USA, pp. 569-601.

Ding, Y., Kuhlbusch, T.A., Van Tongeren, M., Jiménez, A.S., Tuinman, I., Chen, R., Alvarez, I.L., Mikolajczyk, U., Nickel, C., Meyer, J., Kaminski, H., Wohlleben, W., Stahlmecke, B., Clavaguera, S. and Riediker, M. (2017). Airborne engineered nanomaterials in the workplace-A review of release and worker exposure during nanomaterial production and handling processes. $J$. Hazard. Mater. 15: 17-28.

Donaldson, K., Stone, V., Clouter, A., Renwick, L. and MacNee, W. (2001). Ultrafine particles. Occup. Environ. Med. 58: 211-216.

ECHA (2016). Guidance on Information Requirements and Chemical Safety Assessment. Chapter R.15: Consumer exposure estimation. European Chemicals Agency, Helsinki, Finland.

Fischer, H.B., List, E.J., Koh, R.C.Y., Imberger, J. and Brooks, N.H. (1979). Mixing in inland and coastal waters. Academic Press, New York, USA.

Fonseca, A.S., Maragkidou, A., Viana, M., Querol, X., Hämeri, K., de Francisco, I., Estepa, C., Borrell, C., Lennikov, V. and de la Fuente, G.F. (2016a). Processgenerated nanoparticles from ceramic tile sintering:
Emissions, exposure and environmental release. Sci. Total Environ. 565: 922-932.

Fonseca, A.S., Viana, M., Perez, N., Alastuey, A., Querol, X., Kaminski, H., Todea, A.M., Monz, C. and Asbach, C. (2016b). Intercomparison of a portable and two stationary mobility particle sizers for nanoscale aerosol measurements. Aerosol Sci. Technol. 50: 653-668.

Fonseca, A.S., Viana, M., Querol, X., Moreno, N., de Francisco, I., Estepa, C. and de la Fuente, G.F. (2015). Ultrafine and nanoparticle formation and emission mechanisms during laser processing of ceramic materials. J. Aerosol Sci. 88:48-57.

Gakidou, E., Afshin, A., Abajobir, A.A., Abate, K.H., Abbafati, C. et al. (2017). Global, regional, and national comparative risk assessment of 84 behavioural, environmental and occupational, and metabolic risks or clusters of risks, 1990-2016: A systematic analysis for the Global Burden of Disease Study 2016. Lancet 390: 1345-422.

Guichard, R., Tanière, A., Belut, E. and Rimbert, N. (2014). Simulation of nanoparticle coagulation under Brownian motion and turbulence in a differentialalgebraic framework: Developments and applications. Int. J. Multiphase Flow 64: 73-84.

Hämeri, K., Lähde, T., Hussein, T., Koivisto, A.J. and Savolainen, K. (2009). Facing the key workplace challenge: Assessing and preventing exposure to nanoparticles at source. Inhalation Toxicol. 21: 17-24.

Headrick, T.C. (2010). Statistical simulation: Power method polynomials and other transformations. Chapman \& Hall/CRC, Boca Raton, FL, USA.

Hemeon, W.C.L. (1963). Plant and process ventilation. $2^{\text {nd }}$ ed. Industrial Press, New York, USA, pp. 235-245.

Hinds, W.C. (1999). Aerosol technology: Properties, behavior, and measurement of airborne particles. $2^{\text {nd }}$ ed., John Wiley \& Sons Inc., New York, NY, USA, pp. 233-259.

Hussein, T., Dal Maso, M., Petäjä, T., Koponen, I.K., Paatero, P., Aalto, P.P., Hämeri, K. and Kulmala, M. (2005). Evaluation of an automatic algorithm for fitting the particle number size distributions. Boreal Environ. Res. 10: 337-355

Hussein, T., Mølgaard, B. and Hämeri, K. (2011). User influence on indoor aerosol model calibration. Aerosol Air Qual. Res. 11: 309-314.

Hussein, T., Wierzbicka, A., Löndahl, J., Lazaridis, M. and Hänninen, O. (2015). Indoor aerosol modeling for assessment of exposure and respiratory tract deposited dose. Atmos. Environ. 106: 402-411.

Jensen, A.C.Ø., Levin, M., Koivisto, A.J., Kling, K.I., Saber, A.T. and Koponen, I.K. (2015). Exposure assessment of particulate matter from abrasive treatment of carbon and glass fibre-reinforced epoxy-composites - Two case studies. Aerosol Air Qual. Res. 15: 1906-1916.

Jensen, A.C.Ø., Dal Maso, M., Koivisto, A.J., Belut, E., Meyer-Plath, A., Van Tongeren, M., Sánchez Jiménez, A., Tuinman, I., Domat, M., Toftum, J. and Koponen, I.K. (2018). Comparison of geometrical layouts for a multi-box aerosol model from a single-chamber dispersion 
study. Environments 5: 52.

Jianren, F., Hua, Z. and Kefa, C. (1997) Particle concentration and size measurements in two-phase turbulent coaxial jets. Chem. Eng. Commun. 156: 115129.

Jørgensen, R.B., Buhagen, M. and Føreland, S. (2016). Personal exposure to ultrafine particles from PVC welding and concrete work during tunnel rehabilitation. Occup. Environ. Med. 73: 467-473.

Kandler, K., Benker, N., Bundke, U., Cuevas, E., Ebert, M., Knippertz, P., Rodríguez, S., Schützd, L. and Weinbruch, S. (2007). Chemical composition and complex refractive index of Saharan Mineral Dust at Izaña, Tenerife (Spain) derived by electron microscopy. Atmos. Environ. 41: 8058-8074.

Koivisto, A.J., Lyyränen, J., Auvinen, A., Vanhala, E., Hämeri, K., Tuomi, T. and Jokiniemi, J. (2012) Industrial worker exposure to airborne particles during the packing of pigment and nanoscale titanium dioxide. Inhalation Toxicol. 24: 839-849.

Koivisto, A.J., Jensen, A.C.Ø., Levin, M., Kling, K.I., Maso, M.D., Nielsen, S.H., Jensen, K.A. and Koponen, I.K. (2015). Testing the near field/far field model performance for prediction of particulate matter emissions in a paint factory. Environ. Sci. Processes Impacts 17: 62-73.

Koivisto, A.J., Jensen, A.C.Ø., Kling, K.I., Nørgaard, A., Brinch, A., Christensen, F. and Jensen, K.A. (2017). Quantitative material releases from products and articles containing manufactured nanomaterials: Towards a release library. NanoImpact 5: 119-132.

Koivisto, A.J., Kling, K.I., Fonseca, A.S., Bluhme, A.B., Moreman, M., Yu, M., Costa, A.L., Giovanni, B., Ortelli, S., Fransman, W., Vogel, U. and Jensen, K.A. (2018). Dip coating of air purifier ceramic honeycombs with photocatalytic $\mathrm{TiO}_{2}$ nanoparticles: A case study for occupational exposure. Sci. Total Environ. 630: 12831291.

Koponen, I.K., Jensen, K.A. and Schneider, T. (2011). Comparison of dust released from sanding conventional and nanoparticle-doped wall and wood coatings. $J$. Exposure Sci. Environ. Epidemiol. 21: 408-418.

Koponen, I.K., Koivisto, A.J. and Jensen, K.A. (2015). Worker exposure and high time-resolution analyses of process-related dust concentrations at mixing stations in two paint factories. Ann. Occup. Hyg. 59: 749-763.

Lai, A.C.K. and Nazaroff, W.W. (2000). Modeling indoor particle deposition from turbulent flow onto smooth surfaces. J. Aerosol Sci. 31, 463-476,

Landrigan, P.J., Fuller, R., Acosta, N.J.R., Adeyi, O., Arnold, R., Basu, Niladri., Baldé, A.B., Bertollini, R., Bose-O'Reilly, S., Boufford, J. I., Breysse, P.N., Chiles, T., Mahidol, C., Coll-Seck, A.M., Cropper, M.L., Fobil, J., Fuster, V., Greenstone, M., Haines, A., Hanrahan, D., Hunter, D., Khare, M., Krupnick, A., Lanphear, B., Lohani, B., Martin, K., Mathiasen, K.V., McTeer, M.A., Murray, C.J.L., Ndahimananjara, J.D., Perera, F., Potočnik, J., Preker, A.S., Ramesh, J., Rockström, J., Salinas, C., Samson, L.D., Sandilya, K., Sly, P.D.,
Smith, K.R., Steiner, A., Stewart, R.B., Suk, W.A., van Schayck, O.C.P., Yadama, G.N., Yumkella, K. and Zhong, M. (2018). The Lancet Commission on pollution and health. Lancet 391: 462-512.

Levin, M., Gudmundsson, A., Pagels, J.H., Fierz, M., Mølhave, K., Löndahl, J., Jensen, K.A. and Koponen, I.K. (2015). Limitations in the use of unipolar charging for electrical mobility sizing instruments: A study of the fast mobility particle sizer. Aerosol Sci. Technol. 49: 556-565.

Lidén, G. (2006). Dustiness testing of materials handled at workplaces. Ann. Occup. Hyg. 50: 437-439.

Lyyränen, J., Jokiniemi, J., Kauppinen, E.I., Backman, U. and Vesala, H. (2004). Comparison of different dilution methods for measuring diesel particle emissions. Aerosol Sci. Technol. 38: 12-23.

Mølgaard, B., Viitanen, A.K., Kangas, A., Huhtiniemi, M., Larsen, S.T., Vanhala, E., Hussein, T., Boor, B.E., Hämeri, K. and Koivisto, A.J. (2015). Exposure to airborne particles and volatile organic compounds from polyurethane molding, spray painting, lacquering, and gluing in a workshop. Int. J. Environ. Res. Public Health 12: 3756-3773.

Nel, A. (2005). Air pollution-related illness: Effects of particles. Science 308: 804-806.

Oberdörster, G. (2001). Pulmonary effects of inhaled ultrafine particles. Int. Arch. Occup. Environ. Health 74: $1-8$.

Or, C.M., Lam, K.M. and Liu P. (2011). Potential core lengths of round jets in stagnant and moving environments. J. Hydro-environ. Res. 5: 81-91.

Peters, A., Wichmann, H.E., Tuch, T., Heinrich, J. and Heyder, J. (1997). Respiratory effects are associated with the number of ultrafine particles. Am. J. Respir. Crit. Care Med. 155: 1376-1383.

Politis, M., Pilinis, C. and Lekkas, T.D. (2008). Ultrafine particles (UFP) and health effects. Dangerous. Like no other PM? Review and analysis. Global NEST J. 10: 439-452.

Pope, S.B. (2000). Turbulent flows. Cambridge University Press, Cambridge, United Kingdom, pp. 97-122.

Schneider, T. and Jensen, K.A. (2008). Combined singledrop and rotating drum dustiness test of fine to nanosize powders using a small drum. Ann. Occup. Hyg. 52: 2334.

Schripp, T., Wensing, M., Uhde, E., Salthammer, T., He, C. and Morawska, L. (2008). Evaluation of ultrafine particle emissions from laser printers using emission test chambers. Environ. Sci. Technol. 42: 4338-4343.

Seaton, A., MacNee, W., Donaldson, K. and Godden, D. (1995). Particulate air pollution and acute health effects. Lancet 345: 176-178.

Stone, V., Miller, M.R., Clift, M.J.D., Elder, A., Mills, N.L., Møller, P., Schins, R.P.F., Vogel, U., Kreyling, W.G., Jensen, K.A., Kuhlbusch, T.A.J., Schwarze, P.E., Hoet, P., Pietroiusti, A., De Vizcaya-Ruiz, A., BaezaSquiban, A., Teixeira, J.P., Tran, C.L. and Cassee, F.R. (2017). Nanomaterials versus ambient ultrafine particles: An opportunity to exchange toxicology knowledge. 
Environ. Health Perspect. 125: 106002.

Thurston, G.D., Kipen, H., Annesi-Maesano, I., Balmes, J., Brook, R.D., Cromar, K., De Matteis, S., Forastiere, F., Forsberg, B., Frampton, M.W., Grigg, J., Heederik, D., Kelly, F.J., Kuenzli, N., Laumbach, R., Peters, A., Rajagopalan, S.T., Rich, D., Ritz, B., Samet, J.M., Sandstrom, T., Sigsgaard, T., Sunyer, J. and Brunekreef, B. (2017). A joint ERS/ATS policy statement: What constitutes an adverse health effect of air pollution? An analytical framework. Eur. Respir. J. 49: 1600419

Viana, M., Rivas, I., Reche, C., Fonseca, A.S., Pérez, N., Querol, X., Alastuey, A., Álvarez-Pedrerol, M. and Sunyer, J. (2015). Field comparison of portable and stationary instruments for outdoor urban air exposure assessments. Atmos. Environ. 123: 220-228.

Viana, M., Fonseca, A.S., Querol, X., López-Lilao, A., Carpio, P., Salmatonidis, A. and Monfort, E. (2017).
Workplace exposure and release of ultrafine particles during atmospheric plasma spraying in the ceramic industry. Sci. Total Environ. 599-600: 2065-2073.

Viitanen, A.K., Uuksulainen, S., Koivisto, A.J., Hämeri, K. and Kauppinen, T. (2017). Workplace measurements of ultrafine particles - A literature review. Ann. Work Exposures Health 61: 749-758.

Vippola, M., Bard, D., Sarlin, E., Tuomi, T. and Tossavainen, A. (2009). Nanoatlas of selected engineered nanoparticles. Finnish Institute of Occupational Health, Helsinki, Finland.

Received for review, August 30, 2018

Revised, December 14, 2018

Accepted, December 25, 2018 